\title{
Cartografias do não-espaço: Viagens ao fim do mundo na literatura do Holocausto
}

Cartographies of Non-space: Journeys to the End of the World in the Literature of the Holocaust

Cartographies du non-espace: Voyages au bout du monde dans la littérature de l'Holocaute

\section{António Sousa Ribeiro}

\section{OpenEdition}

\section{Journals}

Edição electrónica

URL: http://journals.openedition.org/rccs/430

DOI: $10.4000 /$ rccs.430

ISSN: 2182-7435

\section{Editora}

Centro de Estudos Sociais da Universidade de Coimbra

Edição impressa

Data de publição: 1 Dezembro 2008

Paginação: 05-18

ISSN: 0254-1106

\section{Refêrencia eletrónica}

António Sousa Ribeiro, « Cartografias do não-espaço: Viagens ao fim do mundo na literatura do Holocausto », Revista Crítica de Ciências Sociais [Online], 83 | 2008, colocado online no dia 01 dezembro 2012, criado a 01 maio 2019. URL : http://journals.openedition.org/rccs/430 ; DOI : 10.4000/rccs.430

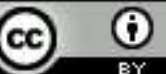




\section{ANTÓNIO SOUSA RIBEIRO}

\section{Cartografias do não-espaço: Viagens ao fim do mundo na literatura do Holocausto'}

A partir de uma reflexão preliminar sobre o conceito de "cartografia fluida", aborda-se o topos da viagem na literatura do Holocausto. São analisados três romances, de Jorge Semprun, Albert Drach e H. G. Adler, concluindo-se que a inversão radical de um dos topoi centrais da modernidade levada a cabo nestas obras aponta para modos de representação do espaço que testemunham paradigmaticamente a prevalência de fronteiras impossíveis de transpor.

Palavras-chave: Holocausto, viagem, Jorge Semprun, Albert Drach, H. G. Adler.

A cartografia moderna pode ser entendida como parte de um acto de domínio, como um aspecto central da apropriação violenta do mundo no decurso da expansão europeia. $\mathrm{Na}$ verdade, um dos pressupostos centrais da dialéctica do Iluminismo consiste em que não subsista a mais pequena parcela de território por cartografar. Este é um pressuposto cujo rasto se encontra em todos os aspectos da história da modernidade, da política à cultura e à ciência. A modernidade não é, contudo, unívoca e unidimensional. Para além da vertente da regulação, expressa na centralidade do Estado e dos seus aparelhos de controlo e disciplina, tem de ter-se em consideração igualmente a vertente oposta da emancipação. A esta luz, o mapa pode também ser visto como uma espécie de narrativa espacial que significa simbolica-

\footnotetext{
${ }^{1}$ Este artigo tem por base uma comunicação apresentada no âmbito da oficina "Fluid Cartographies, New Modernities” do XVIII Congresso da Associação Internacional de Literatura Comparada (Rio de Janeiro, Agosto de 2007). Agradeço a Isabel Capeloa Gil e João Ferreira Duarte o convite para participar na referida sessão. Um agradecimento especial é devido a Maria Irene Ramalho pela leitura atenta que fez da versão original.

A investigação subjacente foi desenvolvida no âmbito do projecto "A Representação da Violência e a Violência da Representação”, financiado pela FCT (POCI/ELT/61579/2004).
} 
mente a celebração utópica da inteligibilidade do mundo e da expansão das possibilidades de experiência humana no mundo.

Como é bem sabido, o mapa tornou-se uma das metáforas centrais do mundo contemporâneo. No contexto da viragem espacial trazida pelo pensamento pós-moderno, essa metáfora liga a noção de um mundo em total interconexão à ideia da simultaneidade da experiência, no quadro de uma compressão extrema do espaço e do tempo. Isto é, ela aponta não apenas para um mundo que é integralmente conhecido, mas também para um mundo que pode ser percebido como uma rede global de relações dinâmicas, em que a comunicação instantânea permite uma mobilidade permanente e as fronteiras estão, aparentemente, a perder o sentido, num processo que oferece possibilidades infinitas ao sujeito cosmopolita.

O topos da viagem, expresso nas múltiplas formas da literatura de viagens, ou da viagem na literatura (as expressões não são, evidentemente, sinónimas), constitui um dos recursos estéticos centrais para a representação da expansão moderna da experiência. A literatura de viagens depende da pré-existência de lugares geográficos e é, desta perspectiva, altamente referencial; por outro lado, contudo, o acto da escrita transforma esses lugares em lugares discursivos, constrói mapas discursivos que se tornam dinâmicos pela intersecção com as específicas temporalidades da viagem e podem bem acabar por revelar-se inteiramente não-referenciais. $\mathrm{Na}$ forma do discurso imperial, a escrita de viagens é um modo de reassegurar a centralidade de uma posição de sujeito confrontando-a com o que se pressupõe e se constrói como os seus outros (Pratt, 1992). Por outro lado, pelo menos desde o Romantismo, esse confronto torna-se também o lugar de um jogo com as identidades no decurso do qual a posição estável do sujeito é posta em questão e, no fim, resulta muitas vezes fragmentada e descentrada. ${ }^{2}$

Desta perspectiva, poderia perguntar-se se a ideia de uma cartografia fluida não tem já uma história bem longa, como pode exemplificar-se de muitas maneiras com a escrita modernista. Não irei, contudo, ocupar-me aqui com este aspecto. Limito-me a observar que, na teoria contemporânea, aquela ideia aponta para a rejeição das dicotomias estabelecidas, das identidades fixas e, em geral, para uma conceptualização da fronteira, não como uma linha divisória, mas como um lugar de encontro em que as relações de poder tendem a dar lugar a formas de tradução entendidas como uma articulação democrática com a diferença. Na verdade, o conceito de hibridação goza, presentemente, de crédito muito elevado e é invocado com frequência como projecção utópica de uma decisiva crítica do poder.

${ }^{2}$ Cf., por exemplo, as reflexões de Manfred Frank sobre o topos da "viagem sem fim” (Frank, 1989). 
Ao sustentarem uma dinâmica complexa e crescente de mobilidade que, sem dúvida, está a originar configurações de identidade inteiramente novas, os processos correntes de globalização abrem um campo favorável a estas conceptualizações. No entanto, a questão não se esgota aqui. O facto é que as fronteiras não estão em vias de desaparecimento: estão simplesmente a mudar de lugar e a adquirir novos sentidos, e uma das tarefas urgentes da teoria crítica é detectar estes processos e chamar a atenção para eles. Noutras palavras: a celebração eufórica da porosidade e da fluidez das fronteiras tem de ser interrogada a respeito dos silêncios e ausências que implica, nomeadamente o silêncio sobre as experiências de confinamento e de exclusão que representam a outra face das possibilidades cosmopolitas oferecidas ao actor de fronteira.

Tendo presente este conjunto de reflexões, escolhi abordar o tópico das transformações das representações do espaço, e das suas implicações para a produção de identidade, do ponto de vista daquela que representa, sem dúvida, a mais extrema experiência de exclusão na modernidade, o genocídio nazi, para o qual usarei a designação hoje corrente de Holocausto. ${ }^{3}$ Irei debruçar-me sobre o que considero serem, por sua vez, exemplos extremos da subversão do motivo da viagem na literatura, três romances publicados nos anos sessenta: Le grand voyage (A longa viagem), de Jorge Semprun; Unsentimentale Reise (Viagem não-sentimental), de Albert Drach; e Eine Reise (Uma viagem), de H. G. Adler. A minha tese principal é que estes três romances, embora de modos muito diversos, delineiam uma cartografia do não-espaço derivada de uma experiência radical de exclusão e confinamento e, enquanto tal, constroem uma crítica poderosa da modernidade. O meu pressuposto é que o Holocausto, como Neil Levi e Michael Rothberg defenderam recentemente, põe a teoria em "dificuldades" - "a espécie de dificuldades teóricas que se recusam a desaparecer”, já que "os acontecimentos do Holocausto representam algo como um limite constitutivo à teoria" (Levi e Rothberg, 2003a: 24). É neste sentido que tomo os textos sobre que irei

\footnotetext{
3 Tenho perfeita consciência das ambiguidades desta designação, a qual, como, entre muitos outros, é salientado incisivamente por Giorgio Agamben (1999), está etimologicamente ligada a uma ideia de sacrifício expiatório. Não apenas, contudo - um facto raramente trazido à colação, mas sublinhado, por exemplo, por Jon Petrie (2000) -, existem exemplos convincentes de um uso secular da palavra pelo menos desde o início do século XX, mas também, o que é talvez mais importante, não é possível recusar o facto de que ela está agora firme e inerradicavelmente instalada no uso corrente. Talvez seja adequado aceitar, como Ruth Klüger, que, neste caso particular, o principal é "que existe uma palavra que pode ser usada sem mais e sem necessidade de qualificações". Uma palavra, em suma, susceptível de proporcionar um "campo de pensamento pacificado" ("umfriedetes Gedankengelände") no qual pode ter lugar um diálogo que faça sentido (Klüger, 1995: 353-54).

Salvo indicação em contrário, todas as traduções são minhas.
} 
debruçar-me como proporcionando uma "irritação" que pode ser aplicada produtivamente a preocupações centrais da teoria contemporânea.

Num dos seus ensaios político-sociológicos, "Ideias para uma sociologia do campo de concentração”, um dos autores que mencionei já, H. G. Adler, escreve que o genocídio nazi representa "um caso extremo [...], especial, de condições existentes, ou, pelo menos, [...] das possibilidades latentes que se encontram em toda a parte na sociedade moderna" (Adler, 1958: 513). Isto de modo nenhum era uma percepção corrente em 1958, uma altura em que o tratamento teórico do genocídio nazi era escasso e, na maior parte, passava despercebido e a acentuação da natureza excepcional do nazismo como um regime "diabólico" era ainda uma interpretação predominante. ${ }^{4}$ A Dialéctica do Iluminismo, de Adorno e Horkheimer, apesar de publicada em 1947, era uma obra praticamente desconhecida (a primeira edição só viria a esgotar-se nos anos sessenta); e Hannah Arendt não tinha ainda cunhado a sua famosa expressão da "banalidade do mal", na sequência do julgamento de Adolf Eichmann, em 1961, cuja ampla ressonância internacional, como é geralmente aceite, representou um marco determinante na tomada de consciência pública do significado do Holocausto (cf., por exemplo, Levi e Rothberg, 2003b: 6-7).

Hoje em dia, a modernidade do Holocausto é uma concepção amplamente aceite. Entre muitas outras referências, pode trazer-se à colação a este propósito o influente livro de Zygmunt Bauman sobre esse tópico. A tese central de Bauman em Modernity and the Holocaust é que "o Holocausto foi o resultado de uma confluência singular de factores que, em si próprios, são perfeitamente ordinários e correntes" na sociedade moderna (Bauman, 1989: xiii). Bauman aparentemente - e estranhamente - não conhece o trabalho pioneiro de H. G. Adler, que não é mencionado na sua obra. Seja como for, a acentuação de que o Holocausto é a consequência extrema da confluência de factores que não são em si mesmos excepcionais é uma noção a reter. É com base nessa noção que irei abordar a inversão distópica do motivo da viagem como topos central da modernidade nos textos que me proponho tratar.

A cartografia do não-espaço a que me referirei não é a cartografia do próprio campo de concentração ou de extermínio, mas sim da viagem para o campo. Nesta viagem, a sucessão de lugares é apenas aparente; na verdade, a própria noção de movimento é apenas aparente, já que acontece, não no tempo, mas num espaço estagnado, rigidamente estruturado, de que estão

\footnotetext{
${ }^{4}$ Thomas Mann, por exemplo, tinha-se feito eco deste mito poderoso no seu grande romance Doktor Faustus (Doutor Fausto), publicado em 1947.
} 
ausentes todos os pontos de referência familiares e que é, assim, percebido pelo sujeito como um não-espaço. Na literatura testemunhal do Holocausto, como é bem sabido, o transporte para os campos, normalmente de comboio, é um aspecto muito comum da narração (Gigliotti, 2006). Na verdade, a viagem de comboio, analisada, por exemplo, por Raul Hilberg em Sonderzüge nach Auschwitz (Comboios especiais para Auschwitz) (Hilberg, 1981), figura como um tropo central da eficácia industrial do genocídio nazi. Não deve também esquecer-se, por outro lado, que apresentar a deportação como uma viagem era uma astúcia utilizada pelos nazis para assegurar a docilidade das suas vítimas. A terrível experiência de estar confinado durante dias em vagões de gado à cunha, sem comida nem água, funcionaria depois como uma experiência disciplinadora extrema, como uma experiência de desumanização literalmente descivilizadora. Era nos comboios que a pergunta formulada por Primo Levi - Se isto é um homem? - podia ser suscitada pela primeira vez no seu pleno e aterrador significado.

Pode parecer absurdo analisar exemplos da ficção testemunhal do Holocausto como narrativas de viagem, mas são os próprios textos, como é desde logo revelado pelos títulos, que se filiam explicitamente nesse género literário. Os textos que vou abordar não se limitam a incorporar a viagem como um aspecto entre outros, eles atribuem uma posição central ao topos da viagem. Assim, uma vez que a resposta específica à questão da crise da representação apresentada por estes textos consiste na sua apropriação subversiva de um topos central da literatura da modernidade, a sua percepção da ruptura insanável causada pelo genocídio nazi e a concomitante crítica da modernidade que levam a cabo são levadas até ao extremo.

É significativo que os três romances tenham sido publicados nos anos sessenta, um facto que aponta para a dificuldade de encontrar formas de lidar com a memória traumática, uma dificuldade subjacente à circunstância de muitos textos relevantes terem vindo a público muito tardiamente, em diversos casos, apenas nos anos oitenta e noventa. ${ }^{5}$ Robert Antelme - que, apesar de tudo, publicou o seu livro L'espèce humaine, um dos primeiros testemunhos relevantes dos campos, em 1947 - designa a dificuldade em termos muito claros:

Tínhamos acabado de regressar, trazíamos connosco a nossa memória, a nossa experiência inteiramente fresca, e tínhamos um desejo irreprimível de a expressar em

\footnotetext{
${ }^{5}$ Um exemplo representativo é a autobiografia já citada da escritora austríaca Ruth Klüger (uma sobrevivente de Auschwitz), weiter leben. Eine Jugend (Continuar a viver. Uma juventude), cuja primeira edição é de 1992.
} 
termos literais. [...] Contudo, isto era impossível. Mal começávamos a contar, ficávamos sufocados. O que tínhamos a dizer começava então a parecer inimaginável a nós próprios. (Antelme, 2004: 9; sublinhado no original)

Não é minha intenção neste ponto envolver-me na discussão interminável sobre a possibilidade ou impossibilidade da representação do Holocausto, uma questão epitomizada no dito de Adorno sobre a barbaridade de escrever poesia depois de Auschwitz (um dito que tem sido citado e glosado até à exaustão e à banalização, a maior parte das vezes sem ter em conta o contexto original e o facto de que o próprio Adorno o revogou mais tarde explicitamente no capítulo "Meditações sobre a Metafísica" da Dialéctica Negativa ${ }^{6}$ ). A questão da representação, contudo, é, evidentemente, basilar no presente contexto, em particular no que toca ao paradoxo do testemunho, tal como se exprime num passo muito citado de I sommersi e i salvati, de Primo Levi:

A uma distância de anos, pode hoje afirmar-se absolutamente que a história dos Lager foi escrita quase em exclusivo por aqueles que, como eu próprio, nunca a mediram até ao fundo. Os que o fizeram não regressaram, ou a sua capacidade de observação foi paralisada pelo sofrimento ou a incompreensão. (Levi, 1989: 6)

A verdadeira testemunha, aquela que "mediu os campos até ao fundo" não pode já falar e, mesmo que isto fosse possível, a voz da testemunha não encontraria ninguém disponível para ouvir. ${ }^{7}$ Assim, a verdadeira experiência dos campos não pode ser propriamente comunicada; a história da literatura do Holocausto pode ser vista como uma busca longa e dolorosa por estratégias discursivas susceptíveis de abordar aquela experiência sem a falsificar. No fim de contas, a questão, tal como foi formulada por Semprun em L'écriture et la vie, não é verdadeiramente que a experiência dos campos seja indizível, mas sim que seja invivível (Semprun, 1995: 19). Sendo assim, a cartografia dos campos não pode senão situar-se num extremo finis terrae, onde toda a percepção com sentido do espaço e do tempo está suspensa e

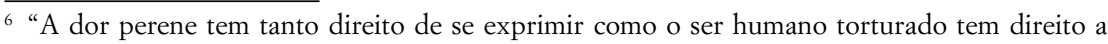
gritar; talvez tenha sido, pois, errado dizer que depois de Auschwitz já não era possível escrever um poema" (Adorno, 1982: 355).

${ }^{7}$ O mesmo paradoxo da testemunha é expresso por Giorgio Agamben (1999) na sua escolha da figura do Muselmann - o prisioneiro que está já para além de qualquer esperança de sobrevivência e, como tal, na prática, deixou de estar entre os vivos - como representante paradigmático do univers concentrationnaire: a testemunha autêntica é, ao mesmo tempo, a que já é definitivamente incapaz de prestar testemunho.
} 
onde, por conseguinte, a lógica da representação atinge um limite aparentemente inultrapassável.

Semprun escreve da perspectiva de alguém que não está sequer certo de ter sobrevivido. Veja-se os seguintes passos de $A$ escrita ou a vida:

Aliás, eu não tinha verdadeiramente sobrevivido. Não tinha a certeza de ser um autêntico sobrevivente. Tinha atravessado a morte, esta fora uma experiência da minha vida. (Semprun, 1995: 127)

Que a vida fosse um sonho depois da realidade do campo, isso é que era aterrorizante. (Ibid:: 141)

Tal como Semprun insistiu repetidamente, em contraste com a famosa asserção de Adorno, a possibilidade do testemunho reside na narrativa literária, isto é, só a transposição para um outro patamar de significação permite fazer justiça à densidade da violenta verdade dos campos de concentração e de extermínio. Nos três casos que irei abordar, o topos da viagem permite a criação de um espaço de representação em que o Holocausto pode ser transformado num evento discursivo. Um tal evento, produto do trabalho da memória, nunca poderá, como é evidente, ser idêntico à experiência original ela própria e, em rigor, nunca poderá reproduzi-la; está, literalmente, deslocado, fora de lugar, mas é justamente este deslocamento que permite ao leitor ter acesso a essa experiência invivível. Esse deslocamento cria em cada caso um cronotopos específico em que o tempo está suspenso e o espaço é construído como o espaço invivível da exclusão e da reclusão. Ao mesmo tempo, ele proporciona também à testemunha os meios ficcionais para escapar à fixação no papel da vítima e para recuperar a sua voz própria.

É esta a estratégia seguida por Semprun em Le grand voyage ( $A$ longa viagem), o seu primeiro grande romance, publicado em 1963, o mesmo ano em que Si questo è um uomo de Primo Levi saiu dos prelos. A experiência do próprio autor (Semprun foi preso pela Gestapo como membro da Résistance e deportado para Buchenwald - iria sempre recusar o estatuto de vítima e insistir, sim, em ser identificado como combatente) espelha-se e, ao mesmo tempo, é deslocada pela voz ficcional do narrador, Gérard. É bem claro que o título, A longa viagem, não aponta simplesmente para a realidade física e a duração da jornada, mas é uma metáfora para uma condição de desenraizamento radical que constitui, do mesmo passo, uma condição de exclusão absoluta. É significativo que o início do romance esteja directamente focalizado na perda do sentido do tempo. Depois de tentativas desesperadas para calcular quanto tempo 
passou desde que o comboio iniciou a sua marcha, Gérard chega a uma conclusão:

Quatro dias, portanto, e três noites. Caminhamos para a quarta noite, o quinto dia. Para a quinta noite, o sexto dia. Mas seremos nós quem avança? Nós estamos imóveis, amontoados uns em cima dos outros, a noite é que avança, a quarta noite, para os nossos futuros cadáveres imóveis. (Semprun, 2002: 9)

Encontramos, assim, logo no início, o paradoxo de uma viagem imóvel. Sally M. Silk chamou a atenção para o facto de que "a consciência da existência espacial" desempenha um papel determinante na narração do romance e, mais especificamente, que "a perspectiva narrativa de Gérard decorre, no plano espacial, exclusivamente a partir do exterior" (Silk, 1992: 2). Na verdade, a posição do sujeito é decisivamente constituída a partir da oposição exterior/interior. A demarcação entre dois mundos que já não têm nenhum ponto de contacto, e muito menos se intersectam, é o fundamento irrevogável da cartografia do romance. Num certo sentido, não voltará a haver um exterior. Numa das prolepses em que se narra o tempo depois da libertação do campo, Gérard aponta penetrantemente para este facto:

Estava fora, mas não conseguia tomar gosto à alegria de estar fora. Tudo acabara, íamos fazer esta viagem em sentido inverso, mas talvez nunca se faça esta viagem em sentido inverso, talvez nunca mais esta viagem se apague. (Ibid.: 23-24)

Ao longo do romance, a voz do narrador, Gérard, dialoga com a voz de uma personagem sem nome, "le gars de Semur", "o tipo de Semur", e, ao mesmo tempo, é duplicada por ela. No final da viagem, no momento em que as portas do vagão são escancaradas pelas SS, esta personagem está morta. Estendendo o corpo do companheiro de viagem no chão, o narrador reflecte:

Estendo o cadáver no pavimento do vagão e é como se depusesse a minha vida passada; todas as recordações que ainda me ligam ao mundo de outrora. (Ibid:: 227)

Ser testemunha da sua própria morte, expressa metaforicamente pela ruptura da temporalidade, a suspensão do tempo, a espacialização da percepção na forma da perda da memória, tal é a experiência extrema transmitida pelo relato ficcional de Semprun. A chegada ao campo veda definitivamente qualquer perspectiva de passar a linha de demarcação que fixa o sujeito a uma posição confinada - a longa viagem termina num ponto sem 
regresso, o ponto de exclusão de toda a possibilidade de uma presença do humano. É, assim, inteiramente lógico que o romance termine com uma frase repetida que percute obsessivamente a mente do narrador: "deixar o mundo dos vivos, deixar o mundo dos vivos" (ibid.: 245).

Os textos de Albert Drach e de H. G. Adler estão muito distantes do estatuto canónico que pode ser reivindicado por $A$ longa viagem. O romance de Semprun recebeu o prestigiado prémio Formentor no próprio ano da publicação, uma distinção que incluía a tradução imediata para diversas línguas (incluindo o português). É um texto muito estudado e frequentemente citado enquanto parte central do cânone da literatura dos campos. Viagem não-sentimental, de Albert Drach, e Uma viagem, de H. G. Adler, publicados, respectivamente, em 1966 e 1962, ocupam, por seu lado, uma posição marginal ao cânone. Apesar de saudados calorosamente por nomes relevantes do campo literário de língua alemã - no caso de Adler, por exemplo, Elias Canetti, Heimito von Doderer e Heinrich Böll - estas obras não conseguiram atingir uma ressonância pública e, embora tenham vindo a atrair uma atenção crescente (Drach recebeu em 1988 o Prémio Büchner, o galardão literário mais relevante da República Federal da Alemanha), ambos os autores são ainda pouco conhecidos.

Viagem não-sentimental, do escritor vienense Albert Drach, forçado ao exílio em 1938, narra uma viagem que, à primeira vista, é muito pouco representativa da literatura do Holocausto. Também começa num comboio, mas num compartimento normal, embora o narrador, o alter ego de Drach, Peter Kucku, deitado num banco num estado de semi-consciência, não consiga lembrar-se de ter comprado bilhete e, aparentemente, não faça ideia de para onde está a ser levado. De facto, embora, neste caso, o narrador esteja a viajar "confortavelmente" (Drach, 1990: 7), o início do "relato" é marcadamente semelhante ao do romance de Semprun: encontramos a mesma prevalência da dimensão do espaço como um espaço de reclusão. Embora o comboio vá avançando sem parar, o sentido do tempo perdeu-se, como é indicado pela perda da memória do narrador, cuja situação é definida pelos traços dominantes do confinamento e da paralisia.

Embora seja preso mais do que uma vez com vista à deportação, o narrador, tendo conseguido, por declarações falsas, o estatuto de "não-judeu", acaba por ser libertado do campo de internamento de Rives Altes e, até ao final da guerra, vai viver escondido no Sul da França. Apesar disso, na linha da argumentação de Ernestine Schlant, o romance pertence indubitavelmente ao complexo da literatura do Holocausto, "se não entendermos como Holocausto apenas o genocídio nos campos de extermínio, mas estendermos a sua aplicação a todos os mecanismos, comportamentos e atitudes que, em 
toda a Europa ocupada pelos nazis, visavam perseguir e aprisionar os judeus para os assassinar" (Schlant, 1993: 35).

O título da narrativa ${ }^{8}$ é, evidentemente, irónico. Laurence Sterne tinha designado a sua obra $A$ Sentimental Journey through France and Italy "uma jornada do coração". A viagem de Sterne reflecte uma condição de harmonia entre o sujeito e o mundo exterior, a experiência do qual permite o alargamento das possibilidades do humano e a afirmação da totalidade do sujeito. A viagem do narrador de Drach é de um tipo completamente diferente. Ele não está confinado num sentido literal e, de certo modo, depois de ter sido libertado do campo de internamento, a sua vida nos bosques, alimentando-se precariamente de cogumelos e de tudo a que consegue lançar mão, poderia mesmo evocar reminiscências de uma espécie de regresso à natureza. O contrário é que é verdade. O motivo da exclusão do mundo dos vivos que já encontrámos em Semprun regressa também aqui repetidamente:

Estou morto desde que deixei o arame farpado de Rives Altes. [...] Tudo o que poderia fazer é transmitir a minha própria morte. É verdade, eu como, bebo, durmo como de costume, mas provavelmente apenas para manter a aparência da vida. (Drach, 1990: 226)

Eu morri, tudo o que eles podem agora fazer é salvar o meu cadáver. (Ibid.: 271)

Aquilo que, à superfície, parece ser uma narrativa de sobrevivência está desde o início ensombrado pela omnipresença do motivo da morte. No final da viagem, só pode estar a morte; mas o permanente adiamento desse fim, que constitui a substância do relato e, aparentemente, dá corpo ao motivo da sobrevivência, não pode oferecer nenhuma real possibilidade de fuga. $\mathrm{Na}$ verdade, embora a viagem do narrador tenha por vezes um carácter de aventura, cada novo episódio não é senão uma confirmação, não do alargamento, mas sim do progressivo estreitamento do espaço da experiência. Tal como o herói de Semprun, Gérard, também ele está preso num espaço confinado, rodeado por uma cerca intransponível, mesmo que, neste caso, invisível, que o limita a uma condição inteiramente exposta (Haagdorens, 2005). É por isso que toda a sua movimentação no decurso do romance se faz em círculos, terminando onde começou, sem nenhum avanço nem progressão no tempo ou no espaço.

\footnotetext{
${ }^{8}$ O subtítulo é "Ein Bericht", "Um relato", criando a ficção de se tratar de um texto de natureza documental, o que a narrativa não é, e postulando uma atitude de distância que se revela essencial para a possibilidade do desenvolvimento do próprio texto.
} 
O fim da narrativa, que é também o fim da jornada, sugere que o narrador se suicida. Isto, no entanto, não é inteiramente claro e fica envolto em ambiguidade, apontando para a irrelevância da morte física de um protagonista que, repetidamente, foi mostrado como estando para além dos vivos. O narrador está deitado numa cama de hotel, num quarto que é "tão estreito como um caixão". Parece cheirar a gás no quarto, talvez ele se tenha esquecido de fechar a torneira do gás. É visitado pela voz de um antigo companheiro de viagem que há muito deve já ter sido assassinado e que evoca os seus momentos finais na câmara de gás, assim unindo ambos os destinos. O narrador gostaria de chorar, mas "os mortos não choram e as lágrimas não são de modo nenhum permitidas numa viagem não-sentimental". As palavras finais do texto têm um sentido emblemático, apontando uma última vez para a inescapável reclusão do protagonista:

"Para onde é que estavas a ir com o teu sonho?"

"Lá para fora", digo. (Ibid.: 368)

Irei agora debruçar-me brevemente sobre o meu terceiro e último exemplo, o romance de H. G. Adler intitulado simplesmente Uma viagem (Eine Reise). Adler é uma figura singular e eminente no âmbito da literatura do Holocausto: na qualidade de sobrevivente de Theresienstadt e Auschwitz, ele escolheu prestar testemunho, não da perspectiva da vítima, mas do cientista. Theresienstadt. 1941-1945. Das Antlitz einer Zwangsgemeinschaft (Theresienstadt. 1941-1945. O rosto de uma comunidade forçada), um livro terminado em 1948 e publicado em 1955, é, seguramente, o primeiro grande tratado sociológico sobre um campo de concentração, um estudo pioneiro daquele complexo a que David Rousset chamou "l'univers concentrationnaire". Baseando-se em notas e documentos reunidos em Theresienstadt e que, quase miraculosamente, puderam ser mantidos a resguardo até à libertação do campo, a obra permanece até hoje uma referência de primeiro plano e desempenhou um papel importante como repositório testemunhal quando, nos finais dos anos cinquenta, os tribunais da República Federal da Alemanha começaram finalmente a levar a juízo funcionários e oficiais nazis responsáveis pelos campos. Para além de outros estudos sobre o genocídio nazi, entre os quais Der verwaltete Mensch ( $O$ ser bumano administrado) (1974), Adler - que, em 1947, fugiu da Checoslováquia para o Reino Unido, adquiriu a nacionalidade britânica e morreu em Londres em 1988 - escreveu poesia e vários romances, alguns dos quais permanecem ainda inéditos. 
Eine Reise tem um fundo autobiográfico: narra a deportação do próprio Adler de Praga, juntamente com a mulher e outros membros da família, nenhum dos quais sobreviveria. A principal estação da viagem é o campo de Theresienstadt, ao qual é dado o nome irónico de Ruhenthal. O romance não visa oferecer um testemunho directo; é um texto de grande complexidade, essencialmente modernista quanto à técnica narrativa e que faz recordar em diversos aspectos o chamado "realismo mágico", pelo uso que faz de uma imagética onírica e pela acentuação da natureza fantasmagórica das coisas e das circunstâncias. O motivo, que já encontrámos em Semprun e Drach, de uma vida que é apenas aparente, porque, na realidade, a morte já ocorreu, percorre todo o romance. As personagens são espíritos ("Geister"), antigos seres humanos ("ehemalige Menschen"), que não têm quaisquer objectivos, "mas também não parecem ter qualquer passado" - "aqui não há a lembrança de nada” (Adler, 1999: 30). A insistência não apenas na falta de um futuro, mas também de um passado, visto que toda a possibilidade da memória foi suprimida, define o tempo do romance como um tempo suspenso, estagnado.

Mas também o espaço é um não-espaço, uma vez que se tornou essencialmente hostil a tudo o que seja humano. A viagem, uma palavra que é obsessivamente reiterada ao longo do romance, é definida desde o início como a figura que designa o absoluto desenraizamento e desabrigo: "Du sollst nicht wohnen!" "Não habitarás!", ibid.: 10). O universo da diegese é tanto mais drasticamente violento quanto assenta na negação de tudo o que alguma vez foi familiar, a ordem das coisas está totalmente alterada, o mais pequeno pormenor da vida tornou-se estranho e hostil de uma forma que faz por vezes lembrar Kafka. A figura da inversão é central no romance, como se revela no tratamento do topos central: a viagem não é um acto empreendido pelas personagens, é alguma coisa que se apoderou delas: "Agora não somos senão os instrumentos de uma viagem sem fim" (ibid.: 51).

Eine Reise contém uma crítica drástica da modernidade que pode bem ser lida paralelamente à Dialéctica do Iluminismo de Adorno e Horkheimer; basta trazer à colação o passo que descreve e louva o crematório ("uma das invenções mais belas e úteis dos tempos modernos"), um passo que traz à memória a descrição da máquina de execução em $\mathrm{Na}$ colónia penal, de Kafka. ${ }^{9}$ Apesar disso, entre os três romances que abordei, Eine Reise é o único que permite um vislumbre de utopia ou pelo menos, da possibilidade

\footnotetext{
${ }_{9}$ Sobre alguns paralelismos e contrastes entre a critica da modernidade de H.G. Adler e de Adorno e as suas posições respectivas a propósito da representação do Holocausto, cf. Adler (2000).
} 
de um futuro. No final do romance, Paul, a personagem que sobreviveu, "quer prosseguir na sua viagem" e "rendeu-se à mão da vida" (ibid.: 303). É uma rendição precária e um fim precário: o significado de "viagem" é restituído a uma temporalidade com sentido, mas a sua violenta inversão levada a cabo ao longo do romance não pode ser simplesmente apagada e permanece como uma interpelação que não terá nunca resposta satisfatória.

Num passo muito citado do seu grande ensaio "Erfahrung und Armut" ("Experiência e pobreza"), Walter Benjamin recorda o aparente paradoxo de que os que regressaram dos campos de batalha da Primeira Guerra Mundial tinham perdido a voz: "Não vinham mais ricos, mas mais pobres no respeitante a uma experiência partilhável” (Benjamin, 1980: 214). Por outras palavras, tinham feito uma viagem que tinha restringido drasticamente, e não alargado, o espaço da sua experiência e o seu universo de comunicação. Uma viagem semelhante à narrada nos três textos que escolhi como exemplos - uma viagem ao lado sombrio da modernidade. Espero que o meu objectivo tenha ficado claro: ao escolher, para tratar o tópico da representação do espaço na modernidade e na pós-modernidade, um exemplo extremo - a experiência do genocídio nazi - baseado na perspectiva do outro que é objecto de exclusão radical, era minha intenção preencher alguns dos espaços centrais de uma cartografia da violência absoluta na modernidade - uma cartografia que poderá servir certamente como chamada de atenção para a persistência de fronteiras intransponíveis nos nossos dias.

\section{Referências bibliográficas}

Adler, H. G. (1958), "Ideas toward a Sociology of the Concentration Camp", The American Journal of Sociology, 63(5), 513-522.

Adler, H. G. (1999), Eine Reise. Wien: Zsolnay.

Adler, Jeremy (2000), “'Die Macht des Guten im Rachen des Bösen’. H.G. Adler, T. W.

Adorno und die Darstellung der Shoah”, Merkur, 614, 475-486.

Adorno, Theodor W. (1982), Negative Dialektik. Frankfurt am Main: Suhrkamp.

Agamben, Giorgio (1999), Ce qui reste d'Auschwitz. L'archive et le témoin. Trad. Pierre

Alferi. Paris: Rivages.

Antelme, Robert (2004), L'espèce bumaine. Paris: Gallimard.

Bauman, Zygmunt (1989), Modernity and the Holocaust. Oxford: Polity Press.

Benjamin, Walter (1980), "Erfahrung und Armut", in W. Benjamin, Gesammelte Schriften. Vol. 4. Org. Rolf Tiedemann; Hermann Schweppenhäuser. Frankfurt am Main: Suhrkamp, 213-219.

Drach, Albert (1990), Unsentimentale Reise. Ein Bericht. München: dtv. 
Frank, Manfred (1989), “Aufbruch ins Ziellose”, in M. Frank, Kaltes Herz, Unendliche Fabrt, Neue Mythologie. Motivuntersuchungen zur Pathogenese der Moderne. Frankfurt am Main: Suhrkamp, 50-92.

Gigliotti, Simone (2006), “'Cattle Car Complexes': A Correspondence with Historical Captivity and Post-Holocaust Witnesses”, Holocaust and Genocide Studies, 20(2), 256-277.

Haagdorens, Liesbeth (2005), "Displacements of Exile in Albert Drach's Novel Unsentimentale Reise”, in Alexander Stephan (org.), Exile and Otherness. New Approaches to the Experience of the Nazi Refugees. Oxford: Peter Lang, 249-268.

Hilberg, Raul (1981), Sonderzüge nach Auschwitz. Mainz: Dumjahn Verlag.

Klüger, Ruth (1995), weiter leben. Eine Jugend. München: dtv.

Levi, Neil; Rothberg, Michael (2003a), "Auschwitz and the Remains of Theory: Towards an Ethics of the Borderland”, symploke, 11(1-2), 23-38.

Levi, Neil; Rothberg, Michael (orgs.) (2003b), The Holocaust: Theoretical Readings. Edinburgh: Edinburgh UP.

Levi, Primo (1989), The Drowned and the Saved. Trans. Raymond Rosenthal. London: Abacus.

Petrie, Jon (2000), "The Secular Word HOLOCAUST: Scholarly Myths, History, and 20th Century Meanings", Journal of Genocide Research, 2(1), 31-63.

Pratt, Mary Louise (1992), Imperial Eyes: Travel Writing and Transculturation. London: Routledge.

Schlant, Ernestine (1993), "Albert Drach's Unsentimentale Reise: Literature of the Holocaust and the Dance of Death", Modern Austrian Literature, 26(2), 35-62.

Semprun, Jorge (1995), A escrita ou a vida. Trad. Maria João Delgado e Luísa Feijó. Porto: Edições Asa.

Semprun, Jorge (2002), A longa viagem. Trad. João Gaspar Simões. Porto: Ambar.

Silk, Sally M. (1992), "Writing the Holocaust/Writing Travel: The Space of Representation in Jorge Semprun's 'Le grand voyage”, Clio, 22(1), 53-65. 